\title{
Infant botulism
}

INSERM

\section{Source}

INSERM. (1999). Orphanet: an online rare disease and orphan drug data base. Infant botulism. ORPHA:178478

Infant botulism is a rare form of botulism (see this term), a rare acquired neuromuscular junction disease with descending flaccid paralysis caused by botulinum neurotoxins (BoNTs). It is due to intestinal colonization by Clostridium botulinum leading to toxinmediated infection with toxemia. 